\title{
An Intercomparison of GPS RO Retrievals with Colocated Analysis and In Situ Observations within Tropical Cyclones
}

\author{
Henry R. Winterbottom ${ }^{1}$ and Qingnong Xiao ${ }^{2}$ \\ ${ }^{1}$ Department of Meteorology, The Florida State University, Tallahassee, FL 32306, USA \\ ${ }^{2}$ College of Marine Science, University of South Florida, Saint Petersburg, FL 33701, USA
}

Correspondence should be addressed to Qingnong Xiao, qxiao@marine.usf.edu

Received 13 January 2010; Accepted 8 April 2010

Academic Editor: Zhaoxia Pu

Copyright ( 2010 H. R. Winterbottom and Q. Xiao. This is an open access article distributed under the Creative Commons Attribution License, which permits unrestricted use, distribution, and reproduction in any medium, provided the original work is properly cited.

\begin{abstract}
Observations from four Global Position System (GPS) Radio Occultation (RO) missions: Global Positioning System/Meteorology, CHAallenging Minisatellite Payload, Satellite de Aplicaciones Cientificas-C, and Constellation Observing System for Meteorology, Ionosphere and Climate and Taiwan's FORMOsa SATellite Mission \#3 (COSMIC/FORMOSAT-3) are collected within a $600 \mathrm{~km}$ radius and \pm 180 minute temporal window of all observed tropical cyclones (TCs) from 1995 to 2006 that were recorded in the global hurricane best-track reanalysis data set (Jarvinen et al. (1984); Davis et al. (1984)). A composite analysis of tropical cyclone radial mean temperature and water vapor profiles is carried out using the GPS RO retrievals which are colocated with global analysis profiles and available in situ radiosonde observations. The differences between the respective observations and analysis profiles are quantified and the preliminary results show that the observations collected within TCs correspond favorably with both the analysis and radiosonde profiles which are colocated. It is concluded that GPS RO observations will contribute significantly to the understanding and modeling of TC structures, especially those related to vertical variability of the atmospheric state within TCs.
\end{abstract}

\section{Introduction}

A tropical cyclone (TC) spends most of its lifetime over the global oceans and often in regions where regularly collected in situ observations are scarce. As a result, the kinematic and thermodynamic structures of TCs were largely unobserved using the conventional observation network. During the mid-1960s through the late 1970s, the advent of aircraft reconnaissance missions provided scientists the ability to create composite analyses of the energy budgets within these events. Many case studies have been executed using the collected data which include Riehl and Malkus [1], Miller [2], LaSeur and Hawkins [3], Gray and Shea [4], Shea and Gray [5], and Jorgensen [6].

More recent advancements, especially for those which apply remote sensing technologies, have provided even more detailed insight into the kinematic and thermodynamic structure for TCs. Example applications include the use of airborne Doppler radar [7-10], stereoscopic and infrared satellite observations $[11,12]$, and field programs [13]. As a result of these observations, further studies investigating the inner-core structures, dynamics, and wind fields of TCs have been performed, which have led to further understandings of the characteristics for TCs.

In 1995, a proof-of-concept mission, GPS/MET ( Global Positioning System/METeorology.) [14, 15] for the Global Positioning System (GPS) Radio Occultation (RO) technique was launched. The GPS RO technique was developed and has been continuously refined by the Jet Propulsion Laboratory (JPL) and Stanford University. Nearly five years after the success of GPS/MET, a collaborative effort between Germany, Argentina, and the United States resulted in the launch of 2 additional experiments-CHAMP ( CHAllenging Minisatellite Payload. ) [16] and SAC-C ( Satellite de Aplicaciones Cientificas-C. ) [17] . Finally, a collaborative effort between Taiwan and the United States (COSMIC/FORMOSAT-3 (Constellation Observing System for Meteorology, Ionosphere and Climate/FORMOsa SATellite Mission \#3.)henceforth COSMIC) resulted in the successful launch of 6 satellites, in addition to still functioning CHAMP. 
For meteorological studies, some of the most appealing characteristics of the GPS RO observations is the large number of observations within the middle latitudes, the high vertical resolution (nearly 100-meter), and the ability of the radio signals to penetrate cloud cover while remaining (largely) unaffected by precipitation. The focus and purpose of this study is to evaluate GPS RO observations collected within TCs and compare to available and colocated in situ observations (radiosondes) and global model analysis profiles. Composite analysis techniques, which are required due to the low horizontal resolution of vertical profiles, are utilized with the intent of providing a basis for which TC GPS RO observations can be used in the initialization Numerical Weather Prediction (NWP) using a variant of data assimilation techniques. The error statistics calculated in this study, between the observations and colocated analysis profiles, provide useful information regarding how the GPS retrieval can be weighted for use in advanced data assimilation procedures.

The remainder of this manuscript is organized as follows: the following section briefly describes the GPS RO technique which is followed by a description of the data collection and sampling methodology used to construct the composite analysis profiles. Section 4 provides a intercomparison of the resulting composite analyses while this manuscript concludes with a discussion and summary of the current results.

\section{The GPS RO Technique as Applied to Meteorology}

The GPS system was first implemented by the military for the purpose of communicating position and time information to different global battle fields. Presently, there are 24 satellites in orbit, each inclined at $55^{\circ}$ to the ecliptic plane. An RO occurs as a GPS satellite- transmitting a radio signal either rising or setting behind the Earth, comes within view of a Low-Earth Orbiting (LEO) satellite with an on-board GPS receiver. As an RO occurs, the transmitted radio signal is Doppler shifted as a result of the atmospheres vertical density gradients. This Doppler shift can be related to the bending angle of the ray path which reflects the integrated effect of refraction along the ray path $[14,16,18]$.

The LEO maintains the position and velocity measurements for each of the GPS satellites. Given the precision of these measurements, the expected Doppler shift of the radio signal can be calculated. Applying a double-difference technique [19], the clock error shift (or excess Doppler shift) is determined from the refracted radio signal. This excess Doppler shift is the measurement obtained by subtracting the observed shift from the clock error shift. The quantities of bending angle $(\alpha)$, impact parameter $(a)$, and tangent point describe this excess Doppler shift [18]. The refraction index $(n)$ is related to the above quantities via

$$
\ln (n(a))=\frac{1}{\pi} \int_{a}^{\infty} \frac{\alpha(x)}{x^{2}-a^{2}} d x .
$$

If the refraction index is assumed constant within each atmospheric layer while the assumption is made that no
TABLE 1: GPS RO missions providing RO measurements through tropical cyclone regions defined via the respective years HBTRA.

\begin{tabular}{lccc}
\hline Mission & Mission ID & Operation & 1DVAR \\
\hline $\begin{array}{l}\text { GPS METeorology } \\
\text { Satellite de Aplicaciones }\end{array}$ & GPS/MET & 1995-1997 & ECMWF \\
$\begin{array}{l}\text { Cientificas-C } \\
\text { CHAllenging Minisatellite }\end{array}$ & SAC-C & 2001-2002 & ECMWF \\
$\begin{array}{l}\text { Payload } \\
\text { Constellation Observing }\end{array}$ & & & \\
$\begin{array}{l}\text { System for Meteorology, } \\
\text { Ionosphere, and Climate }\end{array}$ & COSMIC & 2001 & ECMWF \\
\hline
\end{tabular}

significant asymmetric horizontal variations in temperature and moisture are present [20], the relation in (1) can be solved via an Abel transform [21, 22]. The atmospheric refractivity is then related to various tropospheric, stratospheric, and ionospheric quantities using the following relation:

$$
N=77.6 \frac{P}{T}+3.73 \times 10^{5} \frac{e}{T^{2}}-40.3 \times 10^{6} \frac{n_{e}}{f^{2}} .
$$

Pressure $(P)$ and temperature $(T)$ compose the dry refractivity term while water vapor pressure $(e)$ and virtual temperature constitute the wet refractivity term. Finally, the electron density $\left(n_{e}\right)$ and the carrier frequency $(f)$ contribute the ionospheric refractivity component. For the purposes of tropospheric studies, $n_{e} \approx 0$ and only the variables $P, T$, and $e$ contribute information along the refractivity profile which reduces (2) to

$$
N \approx 77.6 \frac{P}{T}+3.73 \times 10^{5} \frac{e}{T^{2}} .
$$

The calculation to find each of the atmospheric quantities in (3) is inherently an underspecified problem. For the dry atmosphere, the refractivity profile and the hydrostatic equation define $T$ and $P$. However, when water vapor $(e)$ is present, specifically below $10 \mathrm{~km}$, a situation occurs involving 2 equations with 3 unknowns. Independent knowledge of either $T, P$, or $e$ is required to solve for the remaining two variables [23]. Using a 1-dimensional variational (1DVAR) assimilation technique, global analysis fields which have been interpolated to GPS RO positions, allow moisture observation to be obtained from the dry-refractivity profiles [24]. For the GPS/MET, SAC-C, and CHAMP missions, the analyses obtained from the European Center for MediumRange Weather Forecasting (ECMWF) global model provide the analysis profiles for the estimation of $e$ while the National Center for Environmental Prediction (NCEP) Global Forecasting System (formally the Aviation model-GFS/AVN) provide the profiles for the COSMIC retrievals.

\section{Observation Sampling}

This study utilizes both GPS RO observations obtained via the GPS missions listed in Table 1 and the hurricane best-track reanalysis (see, $[25,26]$, Joint Typhoon Warning Center) (HBTRA) data sets during the respective missions. 


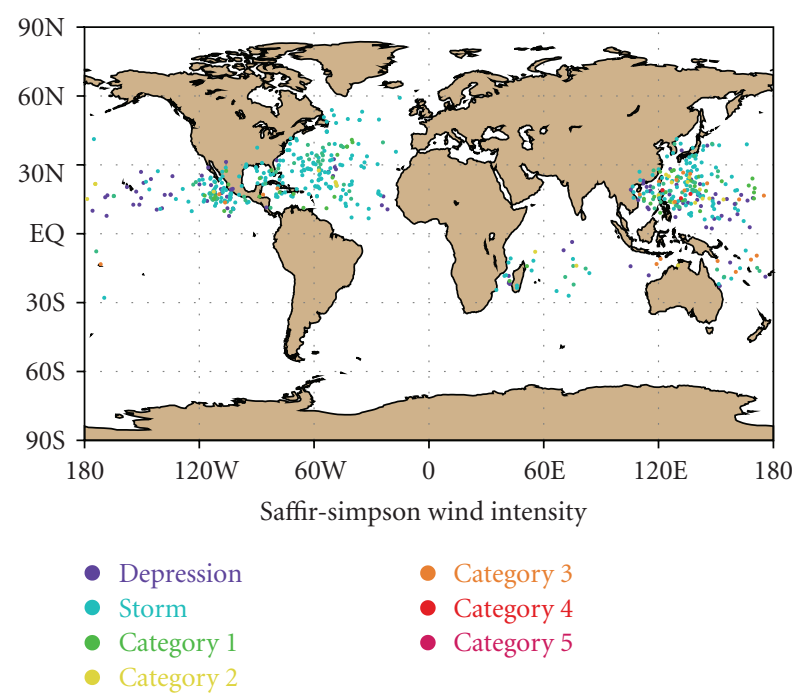

FIgURE 1: GPS RO profiles located within a $600 \mathrm{~km}$ radius and \pm 180 temporal windows of the HBTRA TC positions for each SaffirSimpson intensity classification. 741 observations are collected during the 1995-2006 era within the North-Atlantic, Eastern Pacific, Western Pacific, Southern Indian, and Southern Pacific ocean basins while the respective GPS RO missions are active.

The GPS RO observations are retrieved from the COSMIC online database which also provides colocated global analysis and in situ observational profiles for the respective dryand moist-refractivity profiles. For this study, the moistrefractivity profiles are investigated and compared to the available colocated global analysis and available in situ observation (radio- and dropsonde) profiles. The derivation of the moist-refractivity profile follows the approach of Kursinski et al. [24] discussed above.

The HBTRA contains latitude and longitude positions (at $0.1^{\circ}$ horizontal resolution), minimum central sea-level pressure $(\mathrm{hPa})$ and maximum one-minute surface wind speed (kts). If a GPS RO observation is temporally colocated within \pm 180 minutes and spatial located within a radial distance of $600-\mathrm{km}$ (relative to the TC position in the HBTRA) it is included in the composite analysis. Since TCs are rarely homogenous in size and in order to account for varying translational speeds, the radial distance value of $600-\mathrm{km}$ is chosen so as not to exclude profiles which may have also occurred within the immediate environment surrounding the respective TC. The $600-\mathrm{km}$ radial distance also corresponds to the standard proxy value which defines a TC's radial region of influence (NOAA/NHC/NWS, 1999). This methodology is applied for each of the previously stated missions (see Table 1) in the North Atlantic, Eastern Pacific, Western Pacific, South Indian, and Southern Pacific ocean basins. Figure 1 illustrates the positions of 741 observations which were collected within TCs of the color-coded SaffirSimpson wind-speed intensity classification.

The distribution of observations, as functions of both radial distance and elevation, are nonhomogenous as suggested by Figures 2 and 3. As the relative distance from the observation to the TC center decreases (increases),

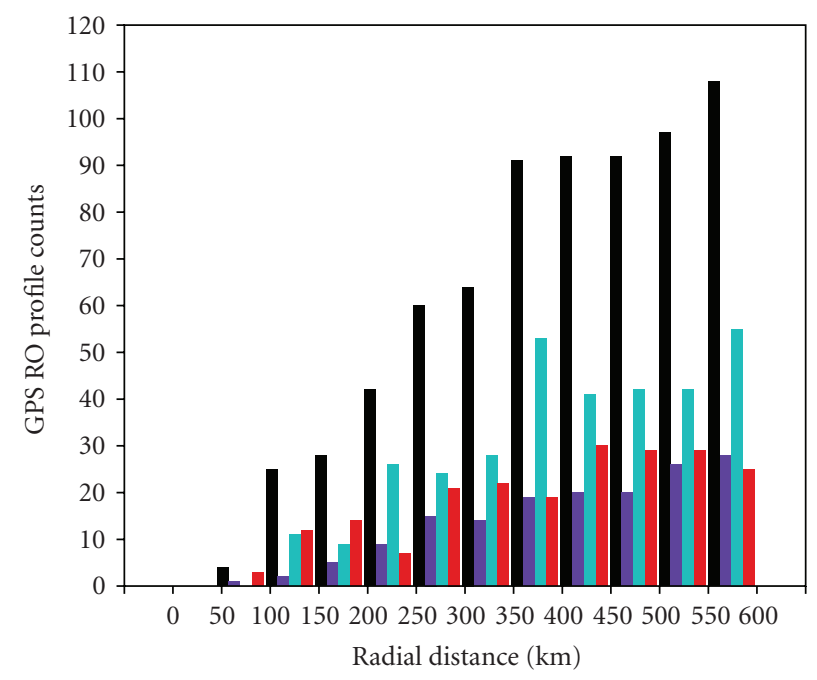

FIgURE 2: Histogram of GPS RO observations collected within depression (purple), tropical storm (cyan), hurricane (red), and all TC (black) environments as a function of radial distance. Radial distance interval is $50 \mathrm{~km}$.

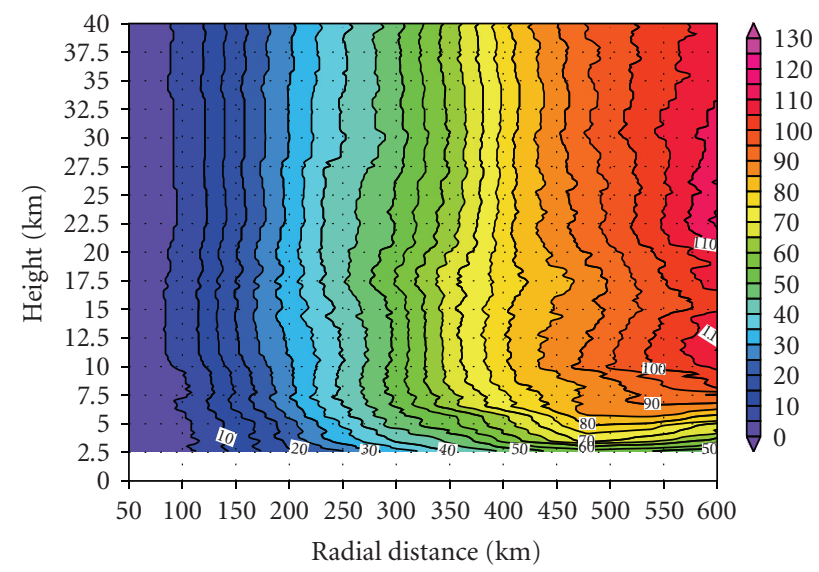

FIgUre 3: Radial cross-section of GPS RO counts for all TCs in different $50 \mathrm{~km}$ radial distance bands. Contour interval is 5 observations.

the number of observations also decreases (increases). The number of observations also increases (decreases) as the elevation increases (decreases). There exists a number of plausible explanations for this phenomenon. Among the possibilities is the impact of water vapor (and the associated gradients) as profiles extend deeper through the troposphere. As shown in Figure 1, a large number of observations are collected between $20^{\circ} \mathrm{S}$ and $20^{\circ} \mathrm{N}$. The tropospheric component with the largest variation in the tropics is water vapor [27]. Water vapor gradients can impact the profiles by inducing instances of super-refractivity [Leroy, S.-personal communication] and multipath propagation [Lohmann, M.,-personal communication]. Another reason for profile truncation may be the GPS-LEO geometry for the RO occurrences. A dry-refractivity profile may be terminated abruptly if the GPS sets behind the Earth's limb before 
reaching a certain depth (distance) into the troposphere. However, determining the precise causes for the vertical depth variances for the collected profiles is not addressed in this study.

The primary assumption made when creating the composite mean structures from the collected observations is of a warm-cored thermodynamic structure. For the extratropical transitioning events (cases typically 40 degrees north and south of the equator), this assumption may not be valid [28-30]. However, as illustrated in Figure 1, a majority of the TCs within which observations are collected occur within the tropics and only some weaker and/or decaying systems persist into the mid-latitudes. It has been shown that weaker TCs and those having undergone extratropical transition may also contain vast asymmetries in their respective thermodynamic fields. These asymmetries, when used to calculate composite means, may result in the creation of features which may appear nonrepresentative of TC thermodynamics. Noting that there remains a large number of observations collected from weaker systems at lower latitudes, we believe the current sample size is large enough to mitigate the profound effects for weak and largely asymmetric systems. Based on Figures 2 and 3, the composite means are calculated from observations collected at radial distances between 200 and $600 \mathrm{~km}$. Although there exists a small sample of observations at radii less than $200 \mathrm{~km}$ (as illustrated in Figures 2 and 3), the inner-core composite appear dramatically different from the results of previous studies [1-6] which may be caused by the aforementioned impact of water vapor gradients which are known to occur within the eye-wall and convective rain-bands of TCs. The composite analyses constructed using the observations collected within the 200 - to $600-\mathrm{km}$ range correspond more readily with the results from previous studies.

\section{Intercomparisons for Observation-Derived Profiles and Colocated Ancillary Profiles}

In order to provide a fair inter-comparison, only GPS RO profiles having either a corresponding colocated global analysis or (in situ) radiosonde profile, are considered for the composite mean calculations. This results in 634 and 209 profiles for the global analysis and radiosonde-derived profiles, respectively. The GPS RO observations are defined along a fixed vertical grid, while the global analysis and in situ (henceforth, ancillary) profiles are defined along irregular vertical grids. Therefore the colocated ancillary profiles are interpolated to the same fixed vertical levels of the GPS RO observations. No extrapolation is performed above or below the maximum and minimum elevations for the respective ancillary profiles. The composite radial mean values are calculated for the observations and ancillary profiles assuming a $50-\mathrm{km}$ radial interval. This interval is chosen in order to minimize the number of missing datum values which occur when using a more narrow distance interval while also attempting to mitigate the impact of smoothing which occurs when using more broad intervals. Only those radial mean values calculated from more than 5 observations within the respective interval are maintained in order to mitigate the effects of erroneous values. These intercomparisons are conducted between the available observations and the derived profiles from the respective colocated ancillary data.

Figure 4 illustrates radial mean comparisons for the composite temperature profiles derived from the GPS RO observations and the corresponding colocated profiles. When comparing the GPS RO retrieved temperature (and moisture) with the global analysis profiles, one expects minimal variance between the respective data sets since the GPS RO moisture profiles are derived using the GPS RO dry-refractivity observations and a 1DVAR assimilation technique to estimate the impact of the characteristics within the atmospheric column nearest to where the respective observation was collected [24]. Inspecting Figures 4(a) and 4(b), we see that this is generally true for the composite temperatures. Figure 4(c) presents the differences between the composite temperatures and colocated global analysis radial mean profiles. The largest values are on the order of $1.5^{\circ} \mathrm{C}$ and generally concentrated within the lower elevations where the GPS RO retrievals are known to be (negatively) impacted by the lower-troposphere moisture gradients. Figures $4(\mathrm{~d})$ and 4(e) are similar to Figures 4(a) and 4(b), but for GPS $\mathrm{RO}$-derived temperature profiles which have corresponding colocated (in situ) radiosonde temperature profiles. Similar features as those seen in the previous comparison are noted. The large differences near the surface (on the order of $3.5^{\circ} \mathrm{C}$ ), as seen in Figure 4(e), are due to erroneous measurements from a colocated radiosonde.

Figure 5 is similar to Figure 4, except that it illustrates radial mean composite computed from the vapor pressure profiles. We consider only the lowest $10-\mathrm{km}$ of the troposphere due to the lack of appreciable water vapor content at higher elevations. Again, small variances between the GPS $\mathrm{RO}$ observations and the colocated global analysis profiles are shown. We note the large number of missing values near the surface in Figure 5(a), due to the aforementioned caveats of the GPS RO retrieval algorithm and subsequent data processing. Figure 5(c) demonstrates that there is general agreement between the observations and analysis, with the greatest difference between the composite observations and analyses is of about $1.6 \mathrm{hPa}$. This is a result of the contrasting resolutions in the observations and the colocated global analysis profiles used to derive the moisture within the respective atmospheric column. It is noted, however, that the majority of the (larger) differences exist near the surface and within the regions impacted by the water vapor gradient induced multipath propagation and/or super-refractivity.

The relationship between observations and colocated comparison profiles is illustrated in Figure 6. All observation values collected from GPS RO moisture retrievals reside along the $x$-axis while the respective comparison profiles are along the $y$-axis. Figure 6(a) compares GPS RO retrieved temperatures $\left({ }^{\circ} \mathrm{C}\right)$ versus colocated global analysis profile temperatures $\left({ }^{\circ} \mathrm{C}\right)$ while Figure $6(\mathrm{~b})$ does the same but for colocated radiosonde temperature profiles. Figures 6(c) and 6(d) are similar, except that they provide an inter-comparison between water vapor pressure $(\mathrm{hPa})$ observations and colocated profiles. There exists a correlation coefficient of 0.997 between the collected GPS RO 


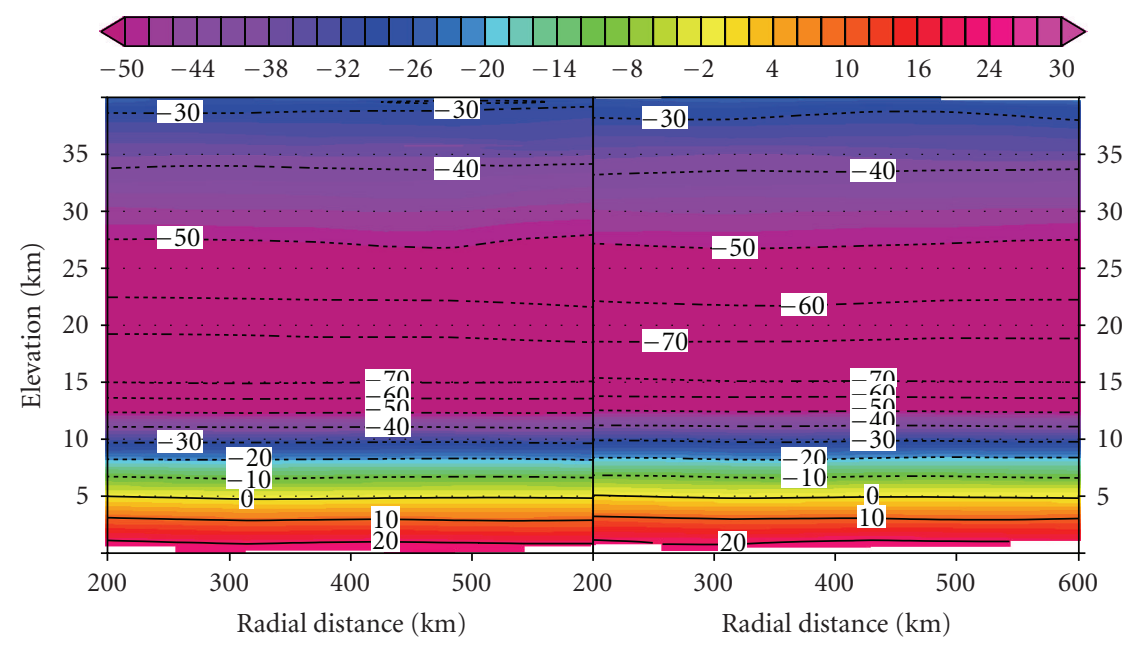

(a)

(d)

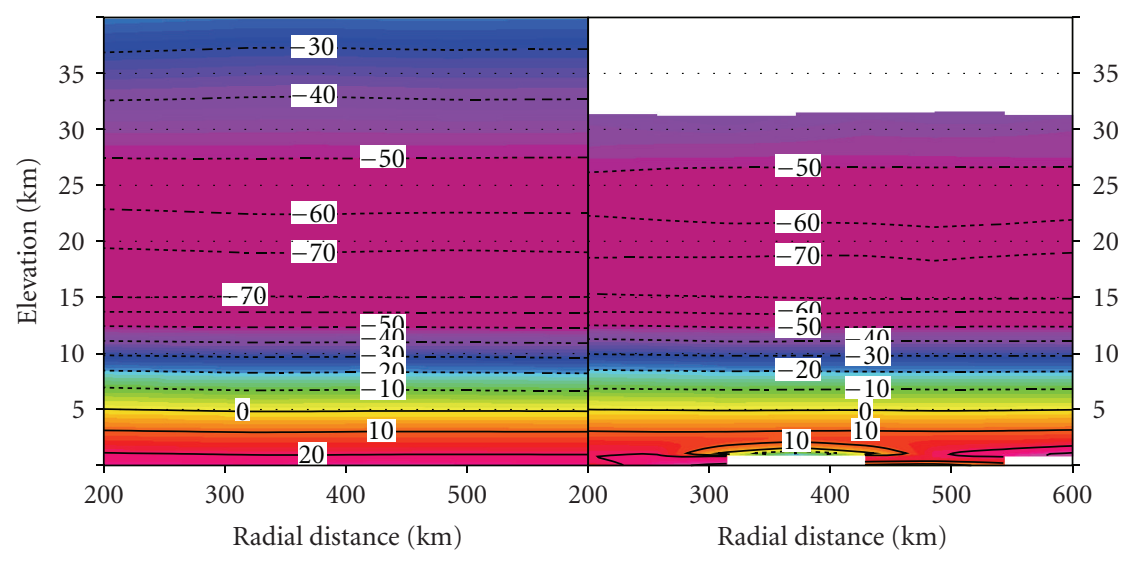

(b)

(e)

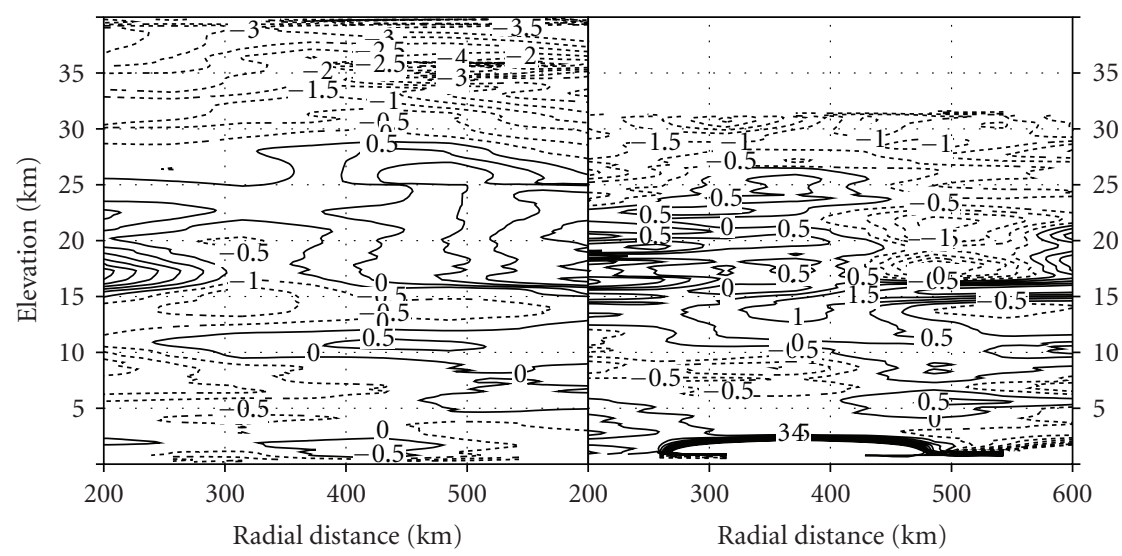

(c)

(f)

Figure 4: Radial mean temperature $\left({ }^{\circ} \mathrm{C}\right)$ intercomparisons for observations colocated with both global analysis profiles and radiosondes. The $x$-axis is radial distance $(\mathrm{km})$ while the $y$-axis is vertical elevation $(\mathrm{km})$. (a) Radial mean temperatures from GPS RO observations with available colocated global analysis profiles. (b) Radial mean temperatures from colocated global analysis profiles. (c) Radial mean differences between colocated observations and global analysis profiles. (d) Radial mean temperatures from GPS RO observations with available colocated radiosonde observations. (e) Radial mean temperatures from colocated radiosonde observations. (f) Radial mean differences between colocated observations and radiosonde observations. White regions in (a), (b), (d), and (e) represent where either the observations or colocated profiles are missing data. 


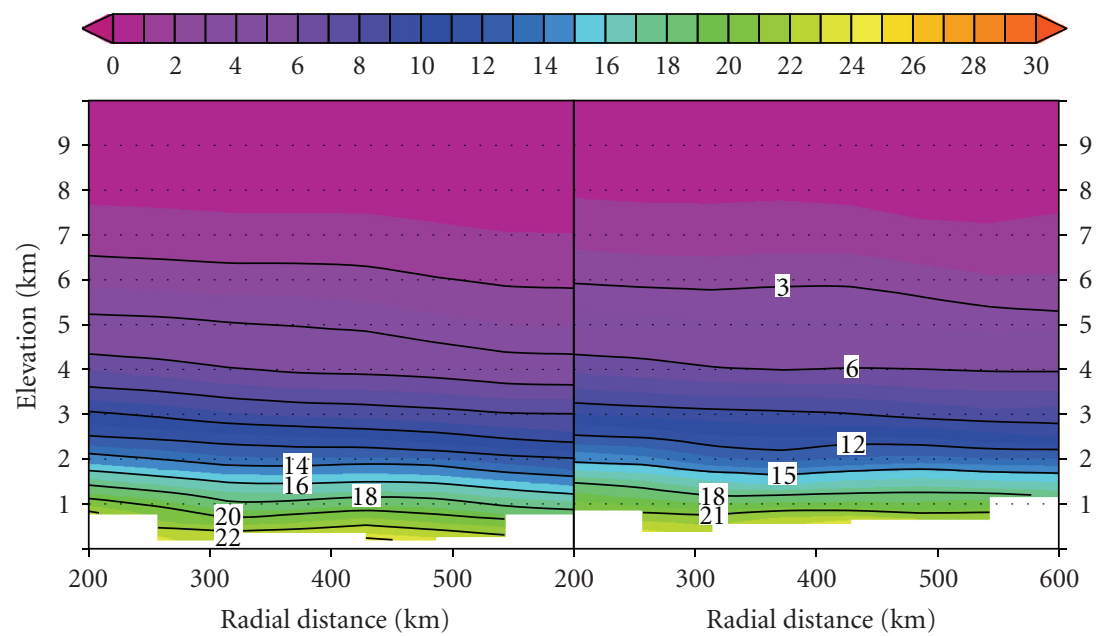

(a)

(d)

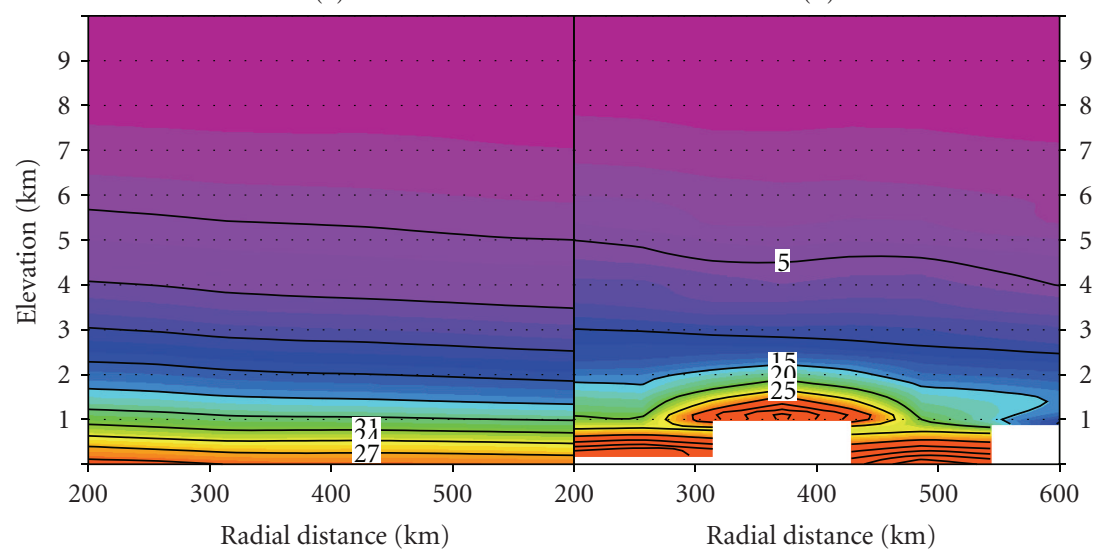

(b)

(e)

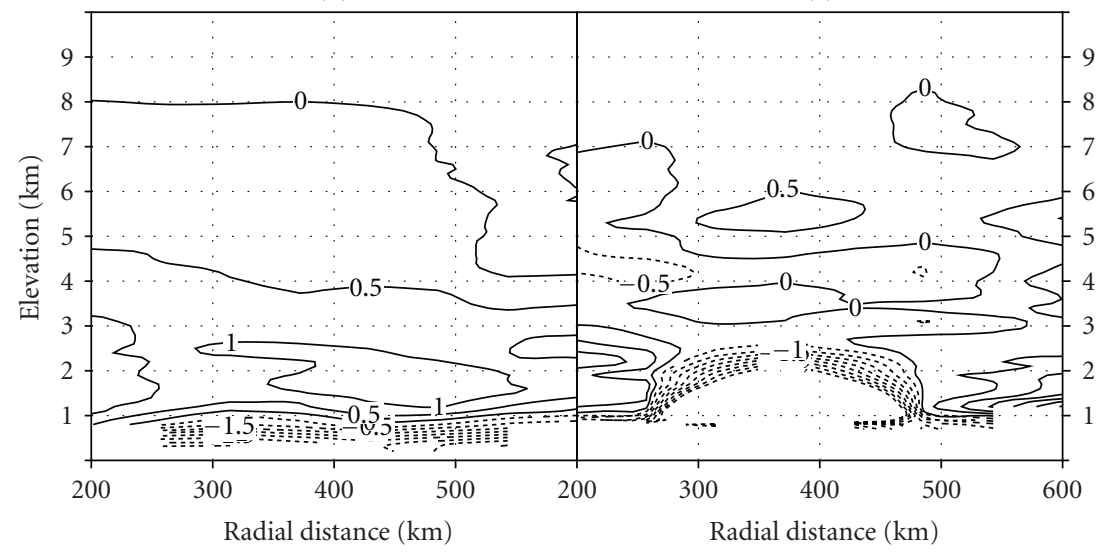

(c)

(f)

FIgURE 5: Same as Figure 4 except for water vapor pressure (hPa). Elevations from the surface to 10-meters are only considered due the lack of appreciable water vapor in the middle- to upper-troposphere.

observations and the colocated global analysis temperature profiles (Figure 6(a)) while and the inter-comparison of the observations and the radiosondes yields a correlation coefficient of 0.994 . The outliers are attributed to errors in the radiosonde observations. Figures 6(c) and 6(d) demonstrate more variability within the water vapor pressure $(\mathrm{hPa})$ fields than within the temperature fields. However, high correlations still exist. The inter-comparison for the collected observations and the colocated global analysis profiles (Figure 6(c)) correlate to about 0.994 while the inter-comparison between the observations and radiosondes (Figure 6(d)) are correlated at approximately 0.892 .

Finally, Figures 7 (a) and 7(b), respectively, illustrate the differences for the mean temperature profiles-for each 


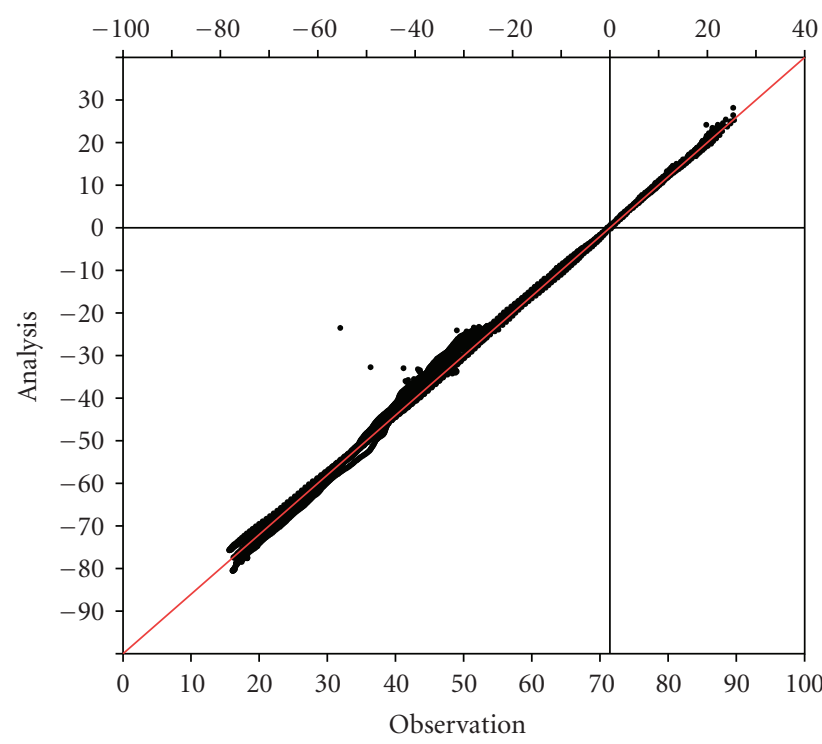

(a)

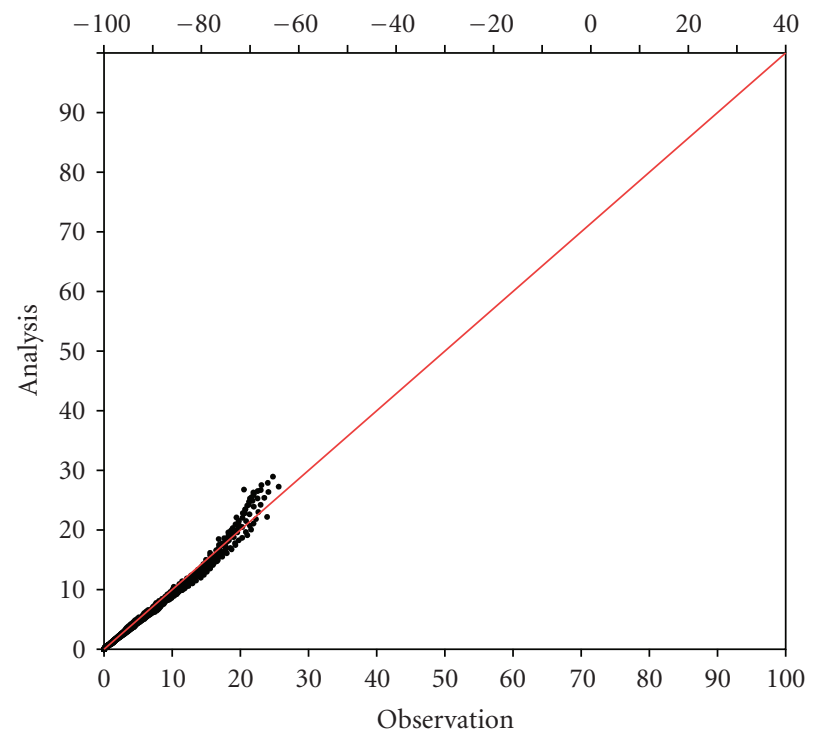

(c)

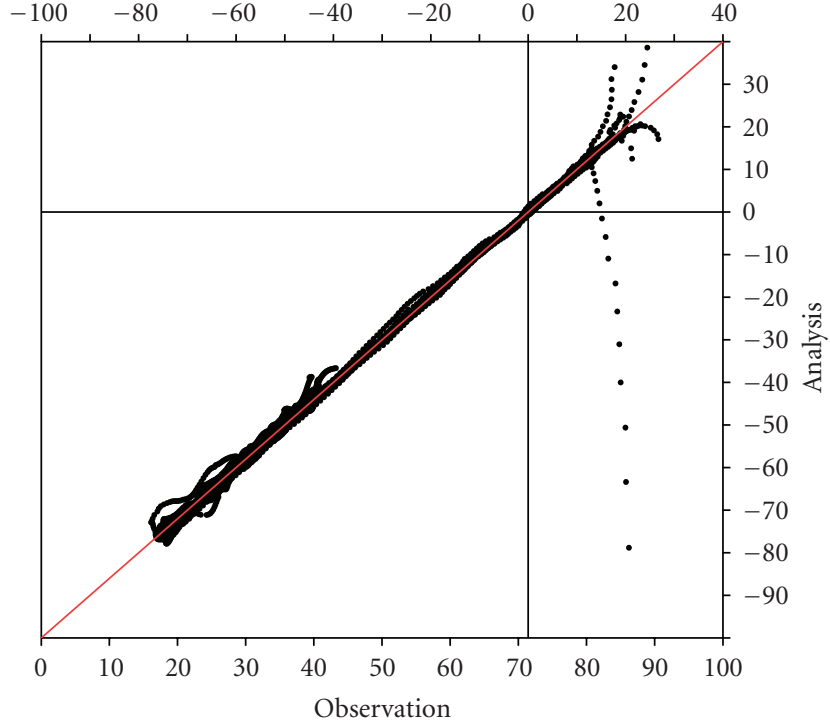

(b)

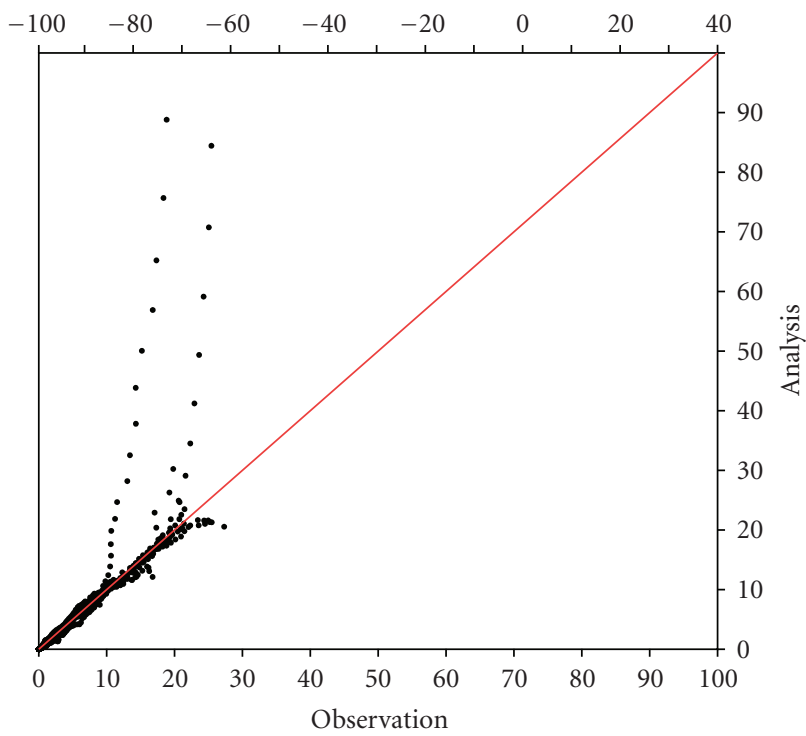

(d)

FIGURE 6: Scatter-plot of observations ( $x$-axis) versus colocated global analysis profiles and/or radiosonde observations ( $y$-axis). Red line represents best-fit line. (a) Radial mean temperature $\left({ }^{\circ} \mathrm{C}\right)$ observations versus radial mean colocated global analysis temperature $\left({ }^{\circ} \mathrm{C}\right)$ profiles. (b) Radial mean temperature $\left({ }^{\circ} \mathrm{C}\right)$ observations versus radial mean colocated radiosonde observation temperature $\left({ }^{\circ} \mathrm{C}\right)$ profiles. (c) Radial mean water vapor pressure (hPa) observations versus radial mean colocated global analysis water vapor pressure profiles, from the surface to $10-\mathrm{km}$. (d) Radial mean water vapor pressure (hPa) observations versus radial mean colocated radiosonde observation water vapor pressure profiles $(\mathrm{hPa})$.

50-km radial interval, which compare observations to the colocated global analysis profiles and radiosondes. The blue shading indicates that the GPS RO retrieved radial mean temperature along the profile is colder than the colocated analysis (or radiosonde) profile, while the red shading indicates that the observation is warmer. Within the lower $15-\mathrm{km}$ of the troposphere, for each radial interval in Figure 7(a), the GPS RO observation temperature is warmer with exception of the $400-\mathrm{km}$ interval which fluctuates slightly by being either warmer or cooler at irregular intervals along the profile. The inversion in the respective profiles represents the mean tropopause height within each interval. Above the inversion (near the tropopause), we see that the observation temperatures are generally cooler than the colocated profiles. Above this layer and into the troposphere, the observations suggest a warmer temperature in the stratosphere than do the colocated profiles. The spread of the blue and red shadings increases as a function of increasing elevation. This 


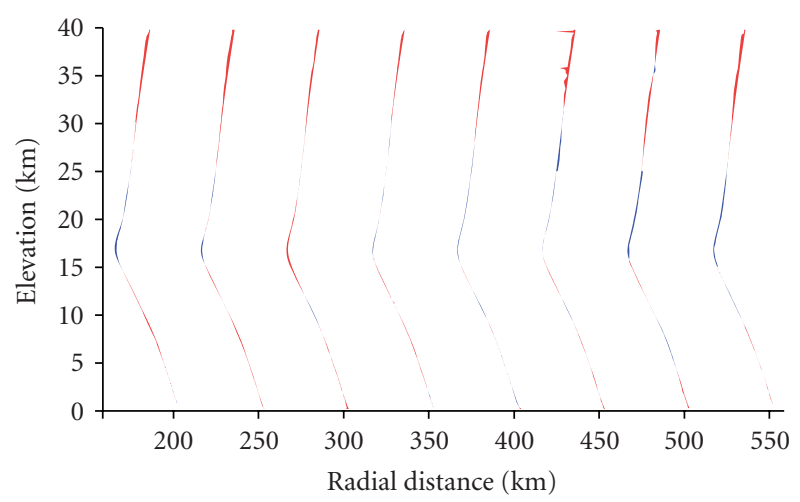

(a)

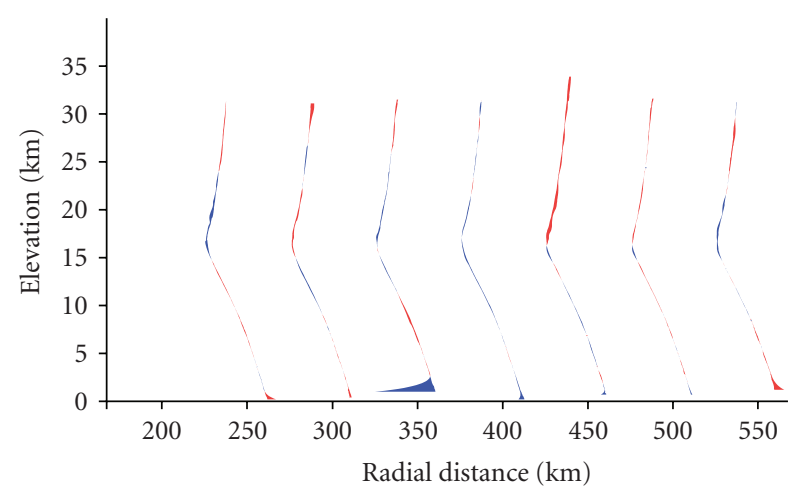

(b)

FIgURE 7: Radial-interval mean intercomparisons for GPS RO observations and (a) colocated global analysis, and (b) colocated radiosonde observation temperature $\left({ }^{\circ} \mathrm{C}\right)$ profiles. Red shading indicates where radial-interval mean temperature is less than the colocated profiles while the blue shading indicates where the observation temperature is greater than the colocated profiles. The $x$-axis represents the radial distance $(\mathrm{km})$ the mean profile while the $y$-axis is vertical elevation $(\mathrm{km})$.

is due to the lack of resolution for the colocated analysis profile resolutions in the upper-troposphere and lowerstratosphere.

Figure 7(b) is similar to Figure 7(a), but for GPS RO observations and colocated radiosonde mean temperature profiles. There are evident spikes which indicate warmer temperatures via the observations $(250-\mathrm{km}$ and $550-\mathrm{km})$ and colder temperatures via the observations $(350-\mathrm{km}, 400-\mathrm{km}$, and $450-\mathrm{km}$ ). In previous discussions we have noted some mean values from the radiosonde analysis profiles which seemed unrealistic (and possibly in error) which may in-part explain the largely colder observational profile at $350-\mathrm{km}$. It is also noted that the radiosonde and observations are not colocated exactly in space and time with the observation, but act as verification for selected GPS RO observations. This offset in time and space, can lead to differences which do not necessarily indicate deficiencies for the temperature derived from the GPS RO. This artifact of the colocation offset may become even more pronounced within TCs. Above $5-\mathrm{km}$, the differences toward a cold or warm bias are small (on the

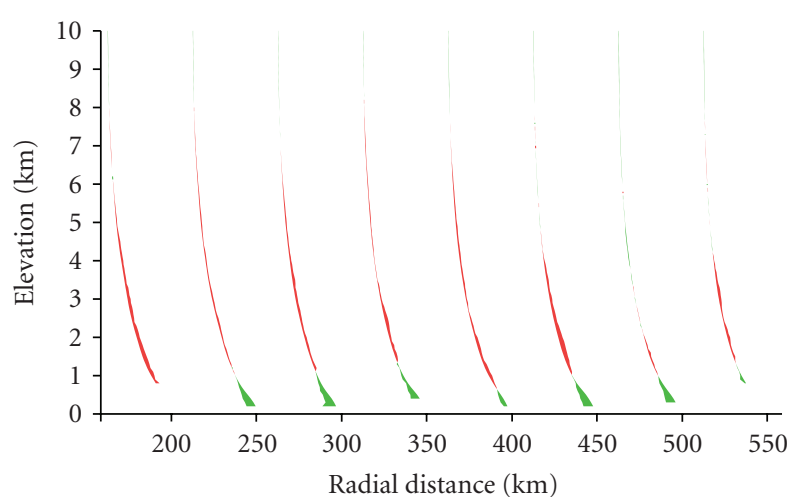

(a)

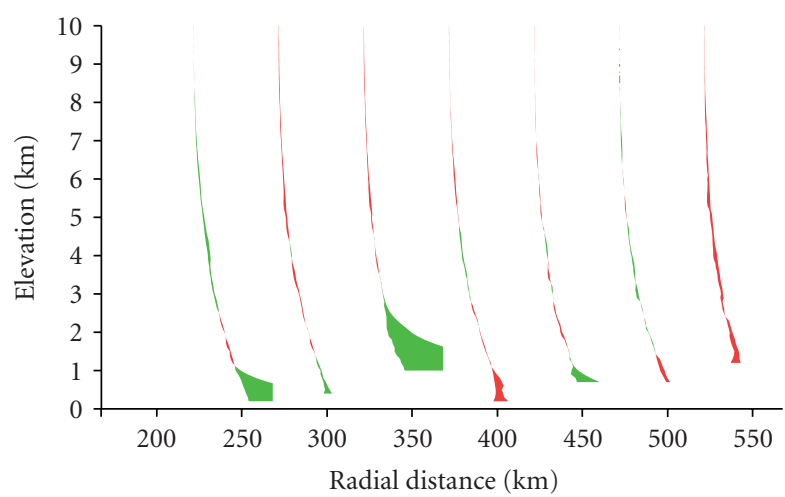

(b)

Figure 8: Same as Figure 7, but for Radial-interval mean intercomparisons for GPS RO observations and (a) colocated global analysis, and (b) colocated radiosonde water vapor pressure (hPa). Elevations from the surface to $10-\mathrm{km}$ are only considered due the lack of appreciable water vapor in the middle- to uppertroposphere. Red shading indicates where radial-interval mean vapor pressure is less than the colocated profiles while the green shading indicates where the observation vapor pressure is greater than the colocated profiles.

order of $1^{\circ} \mathrm{C}$ ) such that we conclude that observations and the colocated radiosonde derived mean temperature profiles are in satisfactory agreement.

Figures $8(\mathrm{a})$ and $8(\mathrm{~b})$ provide analyses similar to those in Figures $7(a)$ and $7(b)$, except for mean water vapor pressure profiles. The red shading indicates where the GPS RO observations are less than the colocated analysis profiles while the green shading indicates that there exists a larger mean vapor pressure than the colocated profiles. For the colocated GPS RO and analysis profiles (Figure 8(a)), the general trend is that the surface observations indicate a greater water vapor pressure than do the colocated analysis profiles. However, it is noted, once again that as the water vapor gradients increase toward the surface, the information obtained from the respective refractivity profile subject to the impacts of multipath propagation and/or super-refractivity. Thus, the accuracy of these profiles should be scrutinized. The mean profiles within the inner 200- to $450-\mathrm{km}$ indicate that the column contains less water vapor than does the colocated analysis profile by approximately $1-$ to $2-\mathrm{hPa}$. 
Beyond a radial distance of $450-\mathrm{km}$, the observations begin to report slightly more water vapor in the column.

Figure 8(b) compares the water vapor pressure meanprofiles from colocated GPS RO observations and radiosondes. We note the large disagreements (larger water vapor pressure content) at $250-$ and $350-\mathrm{km}$. The remaining profiles show a general agreement between the observations and analysis with no more than a 2-hPa bias relative to the colocated analysis profile. The increased spread at $550-\mathrm{km}$ is likely attributed to the previously discussed spatial and temporal offsets.

\section{Summary and Conclusions}

A methodology applied for the collection of 741 GPS RO observations spatially and temporally colocated with TC positions within the HBTRA-from 1995-2006, is employed to assess the quality of GPS RO retrievals collected within TCs. These events often occur in regions known to have large lower-troposphere water vapor gradients and are regions where the GPS RO retrieval algorithm is known to become degraded via multipath propagation and super-refractivity (amongst other effects). In order to understand the impact that these caveats may have on the collected retrievals, available colocated global analysis and in situ radiosonde observation profiles are also collected. Both the global analysis and radiosonde observations provide an inter-comparison, used as a metric to validate the collected observations. It is shown, via the respective intercomparisons, that there exist high correlations between the observations (GPS RO) and analyses (global and radiosonde observations).

Based on the high correlations, it is plausible to suggest that the GPS RO observations-collected within regions, which are often devoid of regular observations-provide a realistic observation of the atmospheric temperature and moisture within the rain-band regions (i.e., 200- to 600$\mathrm{km}$ ) of TCs. The composite methodology cannot represent the small scale variability which may be represented by individual profiles collected within specific TC events. Due to the nonuniform distribution (both temporally and spatially) of the observations, collecting a sufficient number of profiles for the purpose of a similar study using a single event is difficult. However, the opportunity exists, pending the continuation of the GPS missions, to collect more observations (in addition to those presented here), to create an even larger composite data set. These unique profiles provide an opportunity to further both the understanding related to the observational and modeling aspects of TC events. These high-resolution thermodynamic observations within the middle- and upper-troposphere of the TC may help to provide additional insights for the current NWP TC initialization methodologies and as a result contribute to the overall understanding related to the existing NWP deficiencies plaguing TC track and intensity forecasts.

\section{References}

[1] H. Riehl and J. S. Malkus, "Some aspects of Hurricane Daisy, 1958,” Tellus, vol. 13, pp. 181-231, 1961.
[2] B. I. Miller, "On the momentum and energy balance of Hurricane Helene (1958)," NHRP Rep. 53, NOAA Weather Bureau, Miami Office, Miami, Fla, USA, 1962.

[3] N. E. LaSeur and H. F. Hawkins, "An analysis of hurricane Cleo (1958) based on data from research reconnaissance aircraft," Monthly Weather Review, vol. 91, pp. 694-709, 1963.

[4] W. M. Gray and D. J. Shea, “The Hurricane's inner core region. II. Thermal stability and dynamic characteristics," Journal of the Atmospheric Sciences, vol. 30, pp. 1565-1576, 1973.

[5] D. J. Shea and W. M. Gray, "The Hurricane's inner core region. I. Symmetric and asymmetric structure," Journal of the Atmospheric Sciences, vol. 30, pp. 1544-1564, 1973.

[6] D. P. Jorgensen, "Mesoscale and convective-scale characteristics of mature hurricanes. Part I: general observations by research aircraft," Journal of the Atmospheric Sciences, vol. 41, no. 8, pp. 1268-1285, 1984.

[7] F. D. Marks and R. A. Houze, "Inner core structure of Hurricane Alicia from airborne Doppler radar observations," Journal of the Atmospheric Sciences, vol. 44, pp. 1296-1317, 1987.

[8] J. L. Franklin, S. J. Lord, and F. D. Marks Jr., "Dropwindsonde and radar observations of the eye of Hurricane Gloria (1985)," Monthly Weather Review, vol. 116, no. 5, pp. 1237-1244, 1988.

[9] J. L. Franklin, S. J. Lord, S. E. Feuer, and F. D. Marks Jr., "The kinematic structure of Hurricane Gloria (1985) determined from nested analyses of dropwindsonde and Doppler radar data," Monthly Weather Review, vol. 121, no. 9, pp. 2433-2451, 1939.

[10] P. D. Reasor, M. T. Montgomery, F. D. Marks Jr., and J. F. Gamache, "Low-wavenumber structure and evolution of the hurricane inner core observed by airborne dual-Doppler radar," Monthly Weather Review, vol. 128, no. 6, pp. 1653$1680,2000$.

[11] A. F. Hasler and K. R. Morris, "Hurricane structure and wind field from stereoscopic and infrared satellite observations and radar data," Journal of Climate and Applied Meteorology, vol. 25, no. 6, pp. 709-727, 1986.

[12] J. Simpson, R. F. Adler, and G. R. North, "A proposed tropical rainfall measuring mission (TRMM) satellite," Bulletin of the American Meteorological Society, vol. 69, pp. 278-295, 1988.

[13] J. B. Halverson, J. Simpson, G. Heymsfield, H. Pierce, T. Hock, and L. Ritchie, "Warm core structure of Hurricane Erin diagnosed from high altitude dropsondes during CAMEX-4," Journal of the Atmospheric Sciences, vol. 63, no. 1, pp. 309-324, 2006.

[14] R. Ware, M. Exner, D. Feng, et al., "GPS sounding of the atmosphere from low earth orbit: preliminary results," Bulletin of the American Meteorological Society, vol. 77, no. 1, pp. 19-40, 1996.

[15] E. R. Kursinski, G. A. Hajj, W. I. Bertiger, et al., "Initial results of radio occultation observations of Earth's atmosphere using the global positioning system," Science, vol. 271, no. 5252, pp. 1107-1110, 1996.

[16] J. Wickert, C. Reigber, G. Beyerle, et al., "Atmosphere sounding by GPS radio occultation: first results from CHAMP," Geophysical Research Letters, vol. 28, no. 17, pp. 3263-3266, 2001.

[17] R. Colomb, C. Alonso, and I. Nollmann, "SAC-C mission and the International AM Constellation for Earth Observation," in Proceedings of the 3rd IAA Symposium on Small Satellites for Earth Observation, Berlin, Germany, April 2001. 
[18] W. S. Schreiner, D. C. Hunt, C. Rocken, and S. Sokolovskiy, "Precise GPS data processing for the GPS/MET radio occultation mission at UCAR," in Proceedings of the National Technical Meeting of the Institute of Navigation, pp. 103-112, Long Beach, Calif, USA, January 1998.

[19] C. Alber, R. Ware, C. Rocken, and J. Braun, "Obtaining single path phase delays from GPS double differences," Geophysical Research Letters, vol. 27, no. 17, pp. 2661-2664, 2000.

[20] Y. H. Kuo and S. Businger, "COSMIC-Space based GPS," presented at Kona 20-22, March 2007.

[21] G. Fjeldbo and V. R. Eshleman, "The atmosphere of mars analyzed by integral inversion of the Mariner IV occultation data," Planetary and Space Science, vol. 16, no. 8, pp. 10351059, 1968.

[22] G. Fjeldbo, A. J. Kliore, and V. R. Eshelman, "The neutral atmosphere of Venus studies with the Mariner $\mathrm{V}$ radio occultation experiments," The Astronomical Journal, vol. 76, no. 2, pp. 123-140, 1971.

[23] X. Zou, F. Vandenberghe, B. Wang, et al., "A ray-tracing operator and its adjoint for the use of GPS/MET refraction angle measurements," Journal of Geophysical Research D, vol. 104, no. 18, pp. 22301-22318, 1999.

[24] E. R. Kursinski, S. B. Healy, and L. J. Romans, "Initial results of combining GPS occultations with ECMWF global analyses within a 1DVar framework," Earth, Planets and Space, vol. 52, no. 11, pp. 885-892, 2000.

[25] B. R. Jarvinen, C. J. Neumann, and M. A. S. Davis, "A tropical cyclone data tape for the North Atlantic basin, 18861983: Contents, limitations, and uses," Tech. Memo. NHC 22, NOAA/National Hurricane Center, Miami, Fla, USA, 1984.

[26] M. A. S. Davis, G. M. Brown, and P. Leftwich, "A tropical cyclone data tape for the eastern and central North Pacific basins, 1949-1983," Tech. Memo. NHC-25, National Technical Information Service, Springfield, Va, USA, 1984.

[27] D.-Z. Sun and R. S. Lindzen, "Distribution of tropical tropospheric water vapor," Journal of the Atmospheric Sciences, vol. 50, no. 12, pp. 1643-1660, 1993.

[28] R. E. Hart, "A cyclone phase space derived from thermal wind and thermal asymmetry," Monthly Weather Review, vol. 131, no. 4, pp. 585-616, 2003.

[29] J. L. Evans and R. E. Hart, "Objective indicators of the life cycle evolution of extratropical transition for Atlantic tropical cyclones," Monthly Weather Review, vol. 131, no. 5, pp. 909925, 2003.

[30] S. C. Jones, P. A. Harr, J. Abraham, et al., "The extratropical transition of tropical cyclones: forecast challenges, current understanding, and future directions," Weather and Forecasting, vol. 18, no. 6, pp. 1052-1092, 2003. 

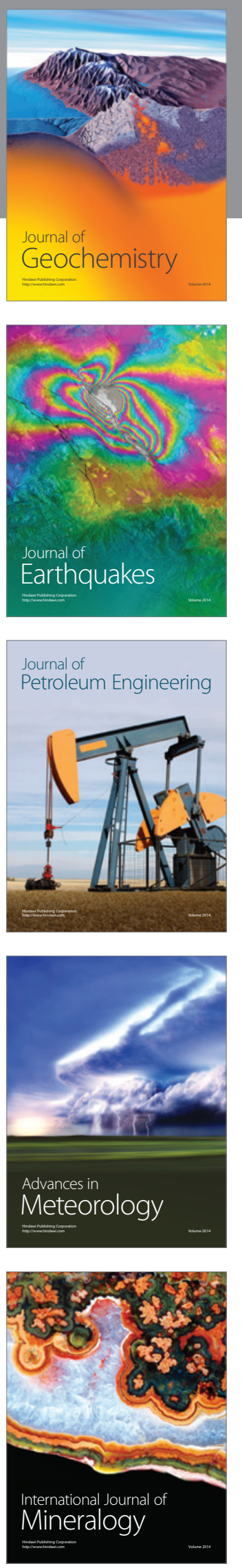
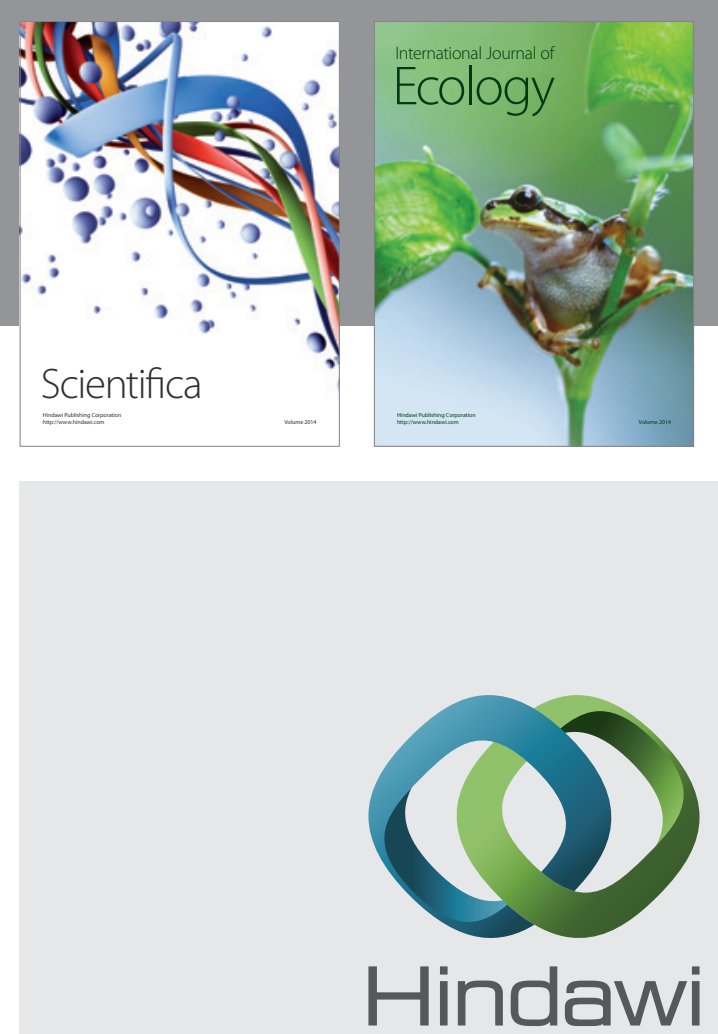

Submit your manuscripts at http://www.hindawi.com
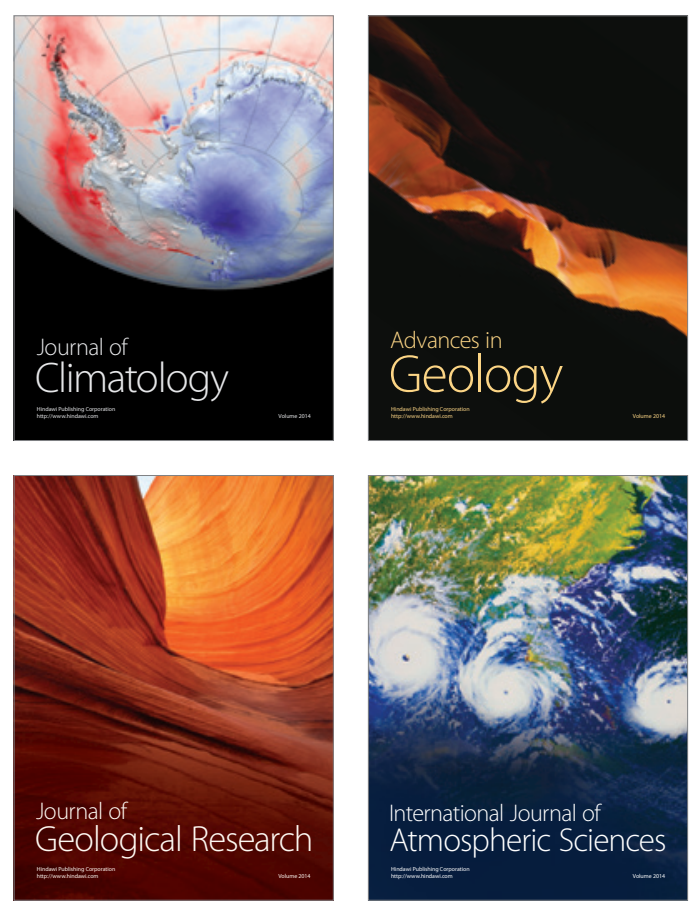
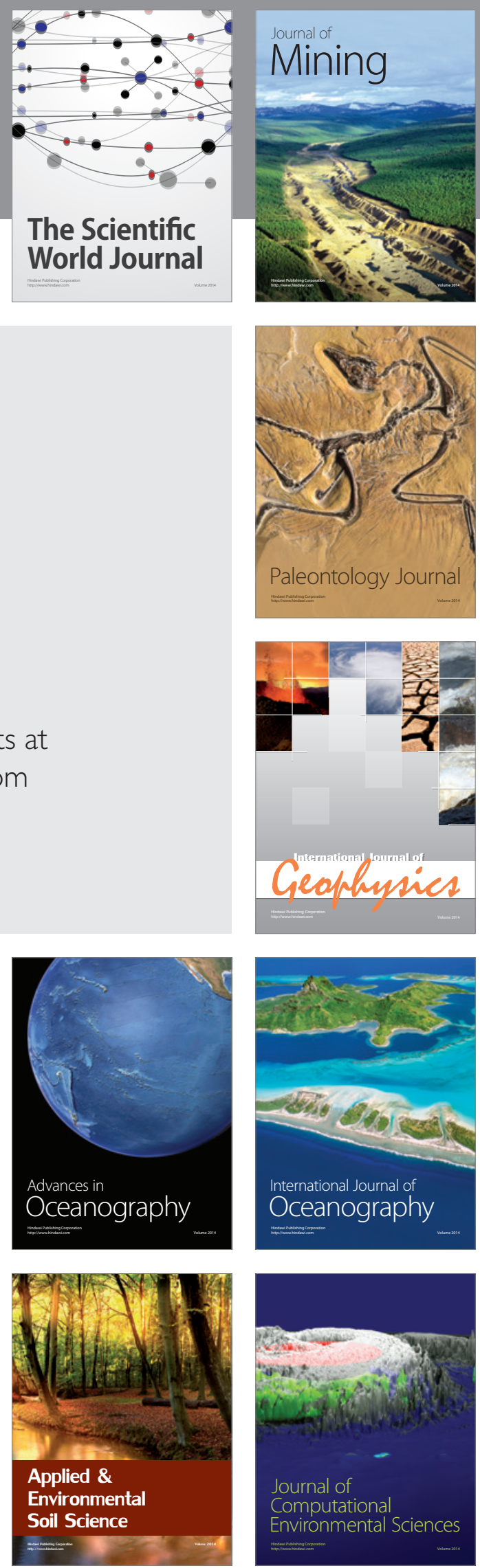